\title{
Diversity, functionality, and resilience under increasing harvesting intensities in woodlands of northern Patagonia
}

\author{
Verónica Chillo $^{\mathrm{a}, \mathrm{b}, *}$, Matías Goldenberg ${ }^{\mathrm{a}, \mathrm{b}}$, Néstor Pérez-Méndez ${ }^{\mathrm{a}, \mathrm{c}}$, Lucas Alejandro Garibaldi ${ }^{\mathrm{a}, \mathrm{b}}$ \\ ${ }^{a}$ Universidad Nacional de Río Negro, Instituto de Investigaciones en Recursos Naturales, Agroecología y Desarrollo Rural (IRNAD), Río Negro, Argentina \\ ${ }^{\mathrm{b}}$ Consejo Nacional de Investigaciones Científicas y Técnicas (CONICET), IRNAD, Río Negro, Argentina \\ ${ }^{\mathrm{c}}$ Institut de Recerca i Tecnologia Agroalimentaries (IRTA), Estació Experimental de l'Ebre, Ctra. Balada Km1, 43870, Amposta, Tarragona, Spain
}

\section{A R T I C L E I N F O}

\section{Keywords:}

Dynamic equilibrium model

Functional diversity

Patagonia

Forest management

Temperate woodlands

Thinning

\begin{abstract}
A B S T R A C T
Sustainable forest management relies on the understanding of biodiversity response to disturbance and the ecological resilience of the system. The dynamic equilibrium hypothesis (DEM) predicts that site productivity will modulate the effects of disturbance gradient on biodiversity. Also, considering functional diversity (ecomorfo-phisicological traits related to resource usage) is needed to understand the effect of species gains and losses on ecosystem functionality. Here we assess the response of understory plant taxonomic and functional diversity to increasing harvesting intensities $(0,30,50$ and $70 \%$ of basal area removed) at three woodland sites of contrasting biomass growth (productivity) in northern Patagonia. Also, we assessed resilience based on comparisons with undisturbed treatments four years after initial harvest. In agreement with DEM, both taxonomic and functional diversity peaked at high, medium, or low harvesting intensities in the high-, medium-, or low-productivity site, respectively. Taxonomic composition was clearly determined by site productivity (biomass growth), while no pattern emerged for functional composition. Functional traits related to light use showed different responses: specific leaf area was only affected by site productivity while leaf chlorophyll content was affected by an interaction between harvesting intensity and site productivity. Interestingly, there was no effect of harvesting intensity on the resilience of taxonomic diversity and functional composition. Only for functional diversity, harvesting intensity was as important as site productivity. In the high and intermediate productivity sites the traits that characterizes the system were more resilient and resembled the control treatment after four years of low or high (but not intermediate) harvesting intensities. Our results support the use of the DEM on forest interventions and the importance of considering both taxonomic and functional composition, as the consideration of functional traits related to resource use strategies have different implications when considering the resilience of the system.
\end{abstract}

\section{Introduction}

Understanding the effect of forest management on biodiversity is important for designing sustainable silvicultural practices. Forest management (e.g. thinning, pruning, harvesting, etc) has been traditionally orientated mainly to products (e.g. timber, biomass), while consequences on biodiversity has been less studied (Puettmann et al. 2015). Nevertheless, nowadays there is consensus that sustainable forestry must maintain and even favor biodiversity for achieving sustainability goals (The Montreal Process 2015). Since in many countries most of forest are on private lands (Mayer and Tikka 2006), linking biodiversity and forest management becomes a prior objective.

Forest harvesting is a common silvicultural practice that affects biodiversity and community structure according to stand complexity and management strategies (Verschuyl et al., 2011; Duguid and Ashton 2013; Root and Betts 2016). In temperate forests, where light availability is a key driver of community composition, canopy opening can increase species diversity, as it promotes a variety of new habitat types and resources (Lencinas et al. 2011; Chillo et al. 2018; Nacif et al. 2020). Yet disturbance effects on biodiversity are not independent of site productivity (Thomas et al. 1999; Cingolani et al. 2005), although few studies consider both factors simultaneously. The Dynamic Equilibrium Model (DEM, Huston 2014) propose that growth rates (productivity) and mortality associated to the disturbance are key processes interacting in their effects on species diversity. This model predicts that site productivity will modulate the effects of the disturbance gradient on diversity (Huston, 2014). Accordingly, plant diversity might peak at high disturbance intensities in high productivity forests while peaking

\footnotetext{
* Corresponding author at: Güemes 383 Of. D (CP 8430), El Bolsón, Río Negro, Argentina.

E-mail address: mchillo@unrn.edu.ar (V. Chillo).
} 
at medium intensities in lower productivity forests (Connell, 1978).

The understanding of the effects of forest management on ecosystem dynamics needs to consider more than just species richness and abundance. Diversity influences ecosystem functioning through the type, range and relative abundance of functional traits (Cadotte et al. 2011). Thus, the analysis of functional diversity allows us to understand the effect of species gains and losses on the functioning of the ecosystem as a whole. For example, functional traits related to the leaf economic spectrum (LES) such as specific leaf area and photosynthetic capacity gives information about resource use strategies of understory plant community (Wright et al., 2004). These traits have a strong correlation that suggest a constrained set of options regarding strategies in leaf production. This is, an economic spectrum ranging from leaves with a quick return on dry mass and nutrient investment (i.e. high specific leaf area and photosynthetic rate, with low life span) to leaves with a slow potential rate of return (i.e. low specific leaf area and photosynthetic rate, but long life span) (Shipley et al., 2006). When considering harvesting intensity as a disturbance, this information can be related to the composition of the community that grew after the disturbance in terms of primary productivity and nutrient cycling, as well as the ecosystem services that depend upon those processes (Lavorel and Grigulis, 2012).

Other important issue for forest management is the understanding of the ecological resilience of the ecosystem, known as its capacity to return to a pre-disturbed condition and still maintain its essential structure and function (Holling, 1973). In general, more productive sites are expected to be more resilient than less productive ones (Stone et al., 1996; Thompson et al., 2009). Nevertheless, few attempts had been done for understanding the consequences of disturbance intensity and site productivity on forest ecosystem resilience (Clarke et al., 2005; Kohv et al., 2013). To add complexity to this issue, both taxonomic and functional identity of the resulting community are important, because species richness may be similar but if the composition differs, the community may change in its functionality (Lipoma et al., 2017). For example, traits such as life form and dispersal mechanisms represent an adaptive response to disturbances and had been proposed to be central for ecosystems resilience (Johnstone et al., 2016). Therefore, in order to design environmentally friendly forest management practices, it is necessary to understand how disturbance and productivity interact for shaping different components of biodiversity (taxonomic and functional) and ecosystem resilience.

Here we analyze the response of taxonomic and functional biodiversity and composition, and resilience to harvesting intensity in Northern Patagonian mixed secondary woodlands, and its recovery after 4 years. We used an experimental approach of systematic harvesting treatments in strips of increasing width and constant length and replicated on three sites with different productivity (growing rates of dominant tree species) (Coulin et al., 2019). Our working hypothesis were: 1) taxonomic and functional diversity will vary with harvesting intensity, and the pattern of the response will depend on site productivity. We predict that sites with greater productivity will tolerate more harvesting intensity, showing higher values of diversity than sites with less productivity sites; 2 ) harvesting releases dominant competitor pressure (for light resource), thus we expect changes in community composition regarding different resource use strategies (mainly light use availability) along harvesting intensity gradient; and 3) the resilience of the ecosystem to harvesting intensity will mainly depend on site productivity. We expect higher resilience at greater productivity sites than at less productivity sites.

\section{Methods}

The north Patagonian Andean region is a Mediterranean type-climate region, with annual precipitation ranging from $920 \mathrm{~mm}$ to $1300 \mathrm{~mm}$ in the Nothofagus antactica distribution, with average annual maximum temperature of $15{ }^{\circ} \mathrm{C}$ and minimum temperature of $1.5{ }^{\circ} \mathrm{C}$. Frosts occur about 120 days a year, with 0.5 dayś hail, annual relative humidity 65\%, and an annual dew temperature of $2{ }^{\circ} \mathrm{C}$ (Reque et al., 2007). Presence of frost is longer in valley bottom, being the less favorable sites for tree growth due to cold air accumulation (Davel and Ortega, 2003).

Three sites with different environmental conditions in the province of Rio Negro, Argentina, were chosen to conduct the study (Figure S1, Table S1). The categorization of site productivity was based on several indicators of site condition (Table S1), but the main index used to determine site productivity was Mean Annual Increment (MAI; $\mathrm{m}^{3} \mathrm{ha}^{-1}$ year $^{-1}$ ), which describes increments in firewood biomass. This index was estimated as firewood volume $\left(\mathrm{m}^{3} / \mathrm{ha}\right)$ extracted from all harvesting intensities by stand age (Table 1 ). The MAI index reflects biomass volume by stand age and it is a direct measure of site quality regarding biomass production. Thus, high, intermediate and low productivity sites refer to sites with greater, intermediate and less firewood biomass growth. Several other variables were considered for the categorization, such as the mean height of dominant trees and on-site exposure, one of the main environmental factors driving forests physiognomy in this region. In southern-exposure hillsides, soils are deeper, have greater development and higher moisture retention than northern hillsides, where soils are drier because are exposed to the dominant northwestern winds and intense summer droughts (Davel and Ortega, 2003). The valley bottom site present specific environmental conditions that are limiting for biomass growth, such as lower temperatures and less precipitation (Table S1). Hence, the high productivity sites, with greater MAI index values, was located on a southern slope $(N$. antarctica dominant height of $6.1 \mathrm{~m}$ ), the intermediate productivity site was placed on a northern slope (dominant height of $3.4 \mathrm{~m}$ ), and the low productivity site, with less MAI index values, was placed on a valley bottom (dominant height of $3.1 \mathrm{~m}$ ) (Table S1) (Coulin et al., 2019).

Vegetation was dominated by mixed $N$. antarctica in the high and intermediate productivity sites were Schinus patagonicus, Lomatia hirsuta, and Embothrium coccineum codominate the stand, and by pure $N$. antarctica in the low productivity site; the only tree species present in all three sites was $N$. antarctica. In the high and intermediate productivity sites, soils were dominated by the group of Hapludands, with dark color, sandy texture, lose structure and abundant presence of roots. The intermediate productivity site had shallower soils and presence of rocks. The groups of Udivitrands were dominant in the low productivity site with ocher color, poor abundance of roots and greater soil depth (Table S1). Elevation across sites range from $790 \mathrm{~m}$ to $840 \mathrm{~m}$.

\subsection{Harvesting treatments}

At each site eight $31.5 \mathrm{~m} \times 45 \mathrm{~m}$ plots were selected. Between 2013 and 2014 six plots were harvested in six strips of increasing width (1.5, 2.5 and $3.5 \mathrm{~m}$; along the plots) with the two remaining plots serving as controls, resulting in 0, 30\%, 50\% and 70\% approximately of basal area removal, respectively. All stems with more than $4 \mathrm{~cm}$ of diameter were classified as firewood leaving smaller branches and leaves in the intervention strips (Coulin et al., 2019; Nacif et al., 2020; Carrón et al., 2020). The design of the interventions was relatively conservative, as we performed a high number of harvesting strips of relatively low width (i.e. low space factor: relation between strips width and canopy height) when compared with common management in other forest ecosystems (Ishii et al., 2008, Mäkinen et al., 2006).

\subsection{Sampling design}

In all plots each species cover was determined by visual estimation in quadrants of $1 \mathrm{~m}^{2}$. We used four quadrants per plot which were placed in the four cardinal points at $2.5 \mathrm{~m}$ from the plot center. Measurements were done during spring of 2015 and 2018. In each measurement all species were identified.

We chose 6 functional traits related to community response to harvesting disturbance (canopy opening), which involves mainly higher 

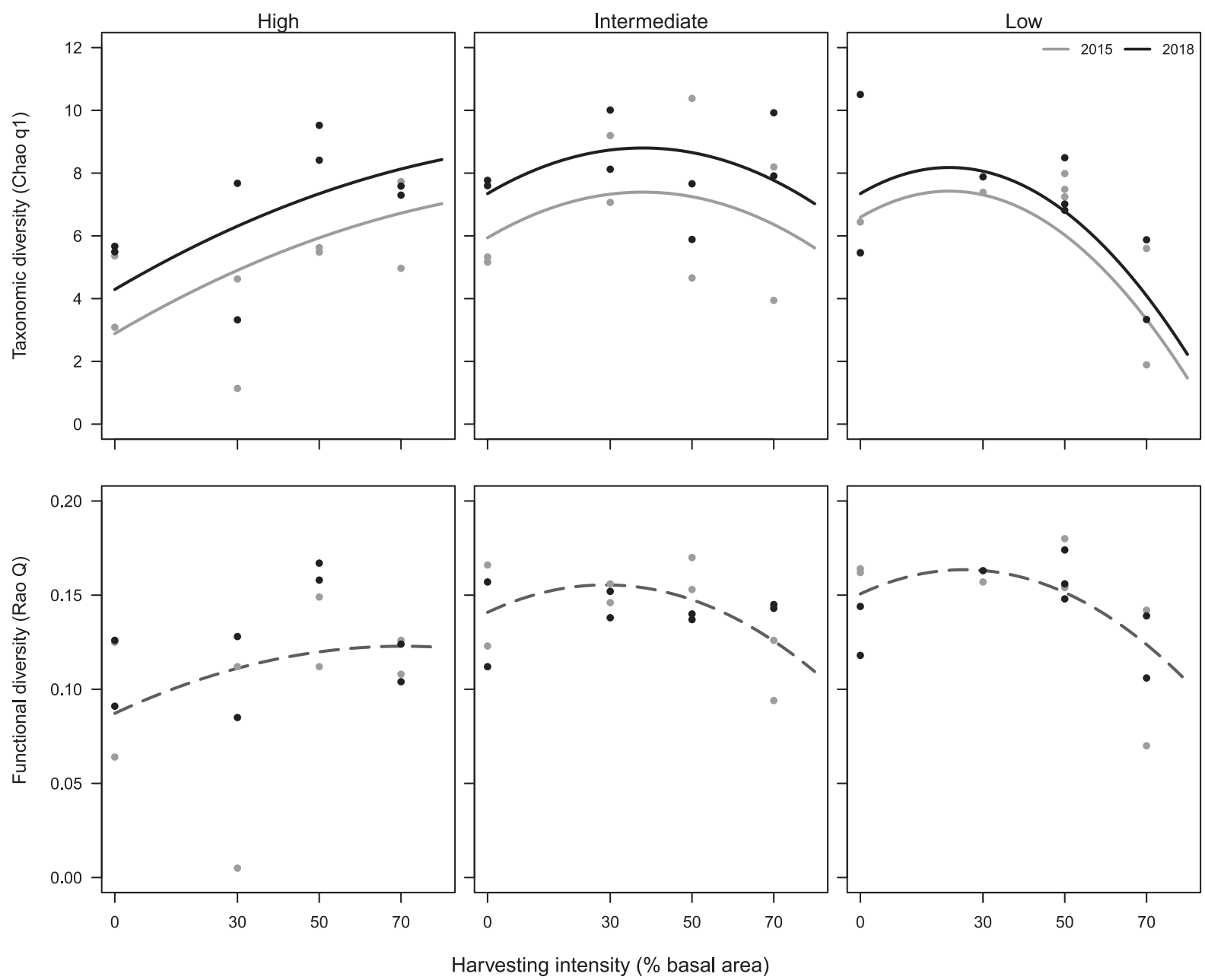

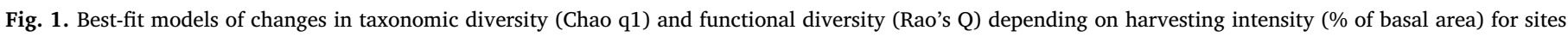

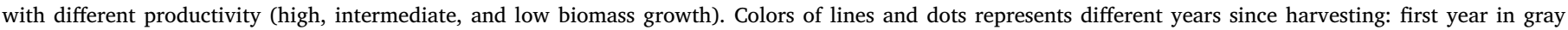
(2015), fourth year in black (2018). Dashed line represents a model without year effect.

light resource availability but also lower soil humidity and desiccation risk. Trait assessment was divided based on trait intra-specific variability. Traits were life form (annual, perennial), growth form (tree, shrub, bambusoid semi-woody, palmoid semi-woody, tussock, rhizomatous herb, rosette herb, extensive-stemmed herb), leaf texture (membranous, intermediate, thought), and seed dispersal mechanism (wind, hydrochory, ballistichory, zoochory, mixed). These traits have low intraspecific variability and were recorded from bibliography and herbarium data, regarding life history information. We also measured specific leaf area (SLA mm ${ }^{2} \mathrm{mg}^{-1}$ ) and leaf chlorophyll content (SPAD ${ }^{\circledR}$ units). These traits have higher intra-specific variability and were measured in the field, in 6 different individuals per site of the most abundant species, following standard methodologies (PérezHarguindeguy et al. 2013).

\subsection{Data analysis}

Taxonomic diversity was assessed by estimating a Chao's q1 index per plot according with the Hill numbers framework proposed by Chao et al (2014). This index can be interpreted as the effective number of common species in the plot where the species are weighted proportionally to their frequencies. To evaluate functional diversity, we calculated two different indexes in order to represent trait diversity and dominant trait values. We decided to use Rao's quadratic entropy index as it considers richness and relative abundance of traits and it is a good measure for identifying assembly patterns underlaying community structure (Mouchet et al. 2010). We decided to use the community weighted mean (CWM) index of different traits, as it calculates the averaged trait value in a given community, weighted by species abundance (Garnier et al. 2004). All index where estimated using FD package (Laliberté et al., 2013) with R software (R Core Team, 2017).

To assess patterns of diversity along disturbance gradients (harvesting intensity) and site productivity on taxonomic (Chao q1) and functional diversity (Rao Q), we fitted linear mixed-effects models. We used lme() function from nlme package for normal distributed data and glmer() function and lme4 package for non-normal distribution data (Bates et al., 2014; Pinheiro et al., 2018). At the plot level, the models considered the fixed effect of harvesting (quantitative predictor), square harvesting (quantitative predictor, to show non-lineal responses to harvesting), site productivity (categorical predictor), year since harvesting (categorical predictor) and plot as a random effect for avoiding pseudo-replications (Zuur et al., 2009, Pinheiro et al., 2018; Coulin et al. 2019). Variances were modeled using VarIdent() function. Multimodel inference was performed and AICc criteria was used to selected the best models following a parsimonious criterion using dredge() function and MuMin package (Barton, 2019). AICc is a correction for small sample size applied to the Akaike information criterion (AIC). Relative importance values of all analyzed variables were calculated with the importance() function in the MuMin package, where the Akaike weights are summed between all models for each explanatory variable (Coulin et al. 2019).

To assess patterns of community composition along harvesting 
intensity and site productivity, we fitted linear mixed-effect models to the community weighted mean of specific leaf area (CWM.SLA) and of leaf chlorophyll content (CWM.LCC). Also, a non-metric multidimensional scaling (nMDS) analysis was done to qualitatively assess changes in community composition considering harvesting intensity (\% basal area), year since harvesting and site productivity (Legendre and Legendre 2012).

To assess community resilience to harvesting for firewood we calculated a change index proposed by Lipoma (2018), which considers the change in time ( 4 years) of the difference between a given harvesting intensity and the control treatment (no harvesting).

$C I=\frac{\left(\left(C_{t 1}-T_{t 1}\right)-\left(C_{t 0}-T_{t 0}\right)\right)}{\left(\left(C_{t 1}-T_{t 1}\right)+\left(C_{t 0}-T_{t 0}\right)\right)} *(-1)$

where $C I$ is the change index, $C$ is the control treatment, $T$ is a given harvesting intensity treatment $(30 \%, 50 \%$ or $70 \%), t 1$ refers to measurement of 2018 and $t 0$ refers to the measurements of 2015 . The index values vary between $1 \mathrm{y}-1$; where 0 indicates no change, positive values indicate that the treatment values get closer (similar) to the control values, and negative values indicates that the treatment values differentiate from the control values (Lipoma, 2018). We calculated this change index for taxonomic diversity (Chao q1) and functional diversity (Rao Q), and for the community weighted mean of specific leaf area (CWM.SLA) and leaf chlorophyll content (CWM.LCC). Finally, we fitted lineal models considering treatment and site as independent variables and $\mathrm{CI}$ as dependent variable, multi-model inference was performed and AICc criteria selected the best models following a parsimonious criterion using dredge() function and MuMin package.

\section{Results}

The best-fit models for taxonomic diversity (Chao q1) always included the year since harvest as a predictor, but year had no effect on functional diversity (Fig. 1). In general, diversity had different patterns of response depending on site identity, where high, intermediate and low productivity sites were categorized based on biomass growth through the MAI index. For the high productivity site, both taxonomic and functional diversity increased with increasing harvesting intensity, while the intermediate and low productivity sites showed diversity peaking at intermediate harvesting intensities. Also, the low productivity site showed the lower levels of taxonomic diversity at higher harvesting intensities (Fig. 1).

The change in community composition under different harvesting intensities and site identity can be seen by analyzing the community weighted mean of traits related to strategies on the use of light and space resources. CWM.LCC varied with both site identity and year since harvest. While the highest value of LCC was found at lowest harvesting intensities in the high productivity, the opposite was found for the intermediate and low productivity sites (Fig. 2). CWM.SLA was not explained by site identity, and only a small effect of year since harvesting was found (Figure S2). All models and the relative importance of the evaluated variables are presented in Table S2 and S3. Also, we present the CWM of categorical traits in Table S4, in a way to visually link the most abundant category of traits such as leaf texture, growth form and seed dispersal mechanism with the harvesting intensity gradient and different site identities. Finally, the nMDS analysis showed different patterns of response between taxonomical and functional composition. While a clear pattern separating composition based on site identity and year since harvesting was found for taxonomic composition, there is no clear pattern of response for functional composition (Figure 3 and S3). For taxonomic composition, sites clearly group based on identity, and almost all showed a similar trajectory with time, approaching each other after 4 years of initial harvesting (Fig. 3).

The change index (CI) indicates changes in diversity and community composition after five years of initial harvesting disturbance. We evaluated this index for Chao q1, Rao Q, CWM.SLA and CWM.LCC. For both community weighted mean indexes (CWM.SLA and CWM.LCC), best-fit models were null models with low relative weight of potential explanatory variables (Table S2 and S3). The best-fit model of the change index of taxonomic diversity (Chao q1) included only site identity as an explanatory variable (Table S2 and S3, Figure S4). The best-fit model of functional diversity (Rao Q) included site identity, harvesting intensity and the interaction between them as explanatory variables, although the importance of the effects was low (Table S2 and S3). High and intermediate productivity sites presented a similar response, with the highest and lowest harvesting intensities being most similar to the control than intermediate harvesting intensities after four years since disturbance; while low productivity sites showed that at lower harvesting intensities the community differentiates the most from control sites (Fig. 4).

\section{Discussion}

Land use change is among the most important drivers of biodiversity loss, and its effects strongly depend on the type, frequency, and severity of disturbance (IPBES, 2019). This opens challenges and opportunities for natural resource management on private lands. Most of the woody species in our study sites are heliophiles and resprouters (Rusch et al. 2017) and exhibit fast initial growth after disturbance, but the response of the community to initial disturbance and potential recovery is not well understood. We designed this study in order to assess patterns and mechanisms on community response and resilience to different intensities of harvesting in a temperate mixed secondary woodland of northwest Patagonia. Our main results show that both taxonomic and functional diversity have similar responses to harvesting intensity under different site productivity (as firewood biomass growth), and that these responses supports the prediction of the dynamic equilibrium model. This means that in sites with higher productivity diversity is not threaten by intermediate or high harvesting intensities for firewood (branches with diameters higher than $4 \mathrm{~cm}$ ). It is important to consider that our results are valid when harvest occurs in small strips of relatively low space factor (relation between strips width and canopy height) compared with other thinning strips widely performed in other forest ecosystems (Ishii et al 2008, Mäkinen et al., 2006), and leaving smaller branches and leaves in the intervention strips. But community composition did not respond in the same way than diversity indices. When considering traits related to the leaf economic spectrum such as leaf chlorophyll content the response seems to be site-specific. Interestingly, the resilience of taxonomic diversity and specific traits was not affected by harvesting intensity, and only the change index of functional diversity could be explained by an interaction of harvesting intensity and site productivity. The specificity of these results shows the importance of considering local conditions and disturbance intensity when planning harvesting for firewood interventions in temperate forests.

Taxonomic and functional diversity changed according to our first working hypothesis; thus, we present evidence for the use of the dynamic equilibrium model (DEM, Huston 2014) in natural resources interventions. We found that the response of taxonomic and functional diversity to harvesting intensity varies according to site productivity, a key finding for sustainable management. Specifically, sites with higher biomass growths (high productivity site) showed a positive response to harvesting intensity, while sites with intermediate and lower biomass growth showed higher diversity at intermediate and low harvesting intensities, respectively. Our results agree with previous work in Patagoniás mix temperate woodlands regarding pollinators diversity (Coulin et al. 2019) and plant taxonomic diversity (Goldenberg 2020) and expands on functional diversity. Similar results had been reported for other type of environments (Agard et al. 1996; Laliberté et al. 2013), but to our best knowledge this is the first study to evaluate diversity and composition, taking in consideration ecosystem functioning, and accept DEM as a useful tool for guiding management decisions in temperate 


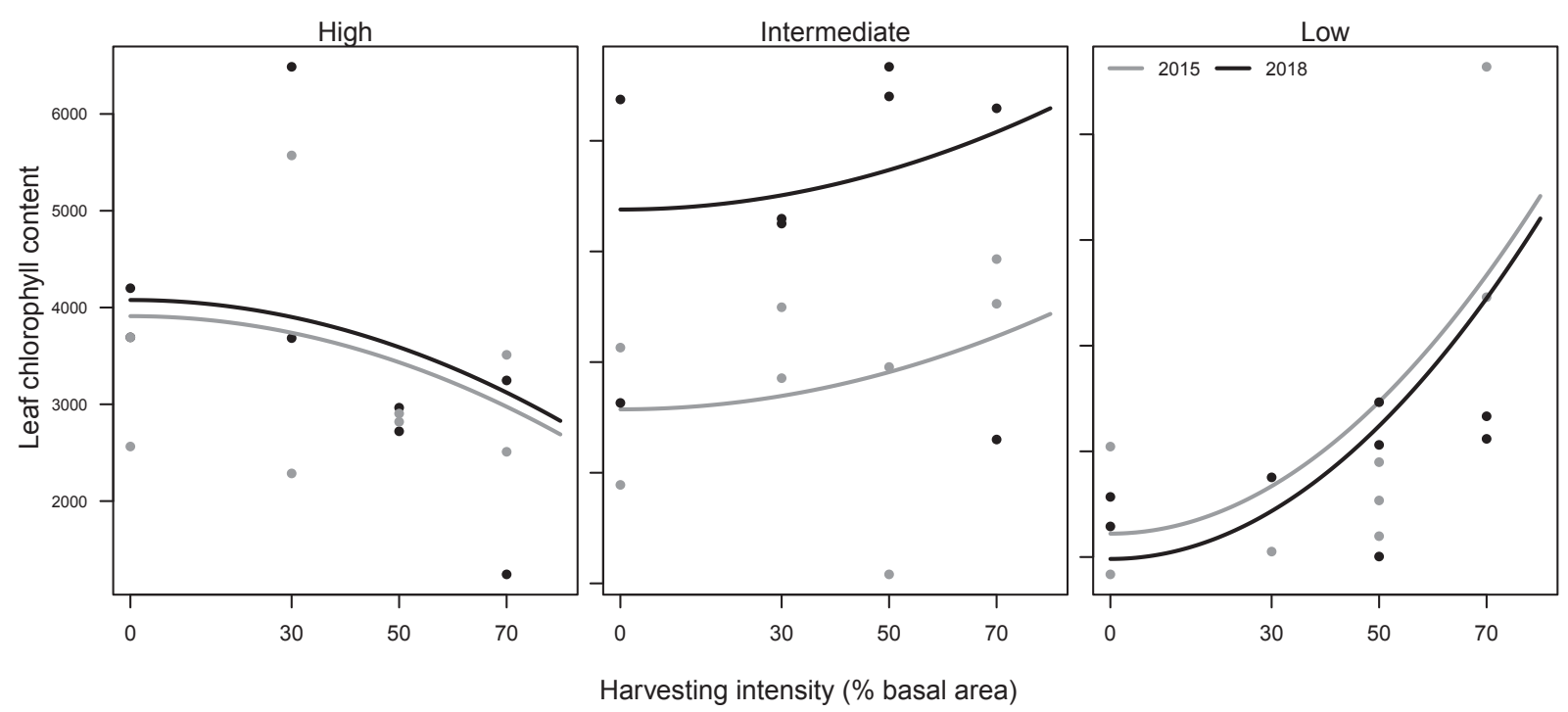

Fig. 2. Best-fit models of changes in community weighted mean values of leaf chlorophyll content (CWM.LCC) depending on harvesting intensity (\% of basal area) for sites with different productivity (high, intermediate, and low biomass growth). Colors of lines and dots represents different years since harvesting: first year in gray (2015), fourth year in black (2018).

forests.

For the analysis of functional diversity, we chose Rao's quadratic entropy because it allowed us to consider both functional richness and divergence of the community, as it considers species abundance in the analysis (Botta-Dukat, 2005). Moreover, the use of Rao's index had been found to properly identify assembly rules as it can differentiate limiting similarity from niche filtering and random assembly (Mouchet et al., 2010). In our case study, higher values of functional diversity imply higher functional richness and/or functional divergence of traits related to the use resources such as light and space. High harvesting intensities may reduce competitive ability of dominant species, resulting in a release of available resource that enable the coexistence of species with a broad range of functional traits (Miedema et al. 2019; Williams et al. 2020).

Bringing functional diversity and composition together at the community level shed light on the process behind community change after disturbance. We predicted changes in community composition along the leaf economic spectrum (mainly light use availability) under different harvesting intensities, but our hypothesis was partly demonstrated as no straightforward pattern emerged from the analysis. A trend can be seen, where the change in understory composition after harvesting varied depending on site identity. In the high productivity sites under low harvesting intensities the community was characterized by a resource conservation strategy (high leaf chlorophyll content, shrubs). Higher harvesting intensity changed community towards a fast resource use strategy, with lower leaf chlorophyll content. In this new community, rhizomatous herbs, and other species with intermediate to membranous leaf texture gain importance. But there was no effect of site productivity or harvesting intensity on specific leaf area. Notably, the opposite response was found in low productivity sites, where undisturbed communities are characterized by lower levels of leaf chlorophyll content and higher harvesting intensity changed the community towards a resource conservation strategy, mainly dominated by bambusoid semi-woody and shrubs. These trade-offs in competitive ability had been recognized as important in predicting diversity response when disturbance returns resources to the ecosystem (Haddad et al. 2008), which is the case of harvesting for firewood in temperate forests. The lack of a clear pattern to the predictions of the leaf economic spectrum trade-off at a local scale agrees with recent findings, where trait plasticity seems to play an important role in the response to local environmental responses, and similar species may respond differently to different drivers (Wright and Sutton-Grier 2012; Williams et al. 2020).
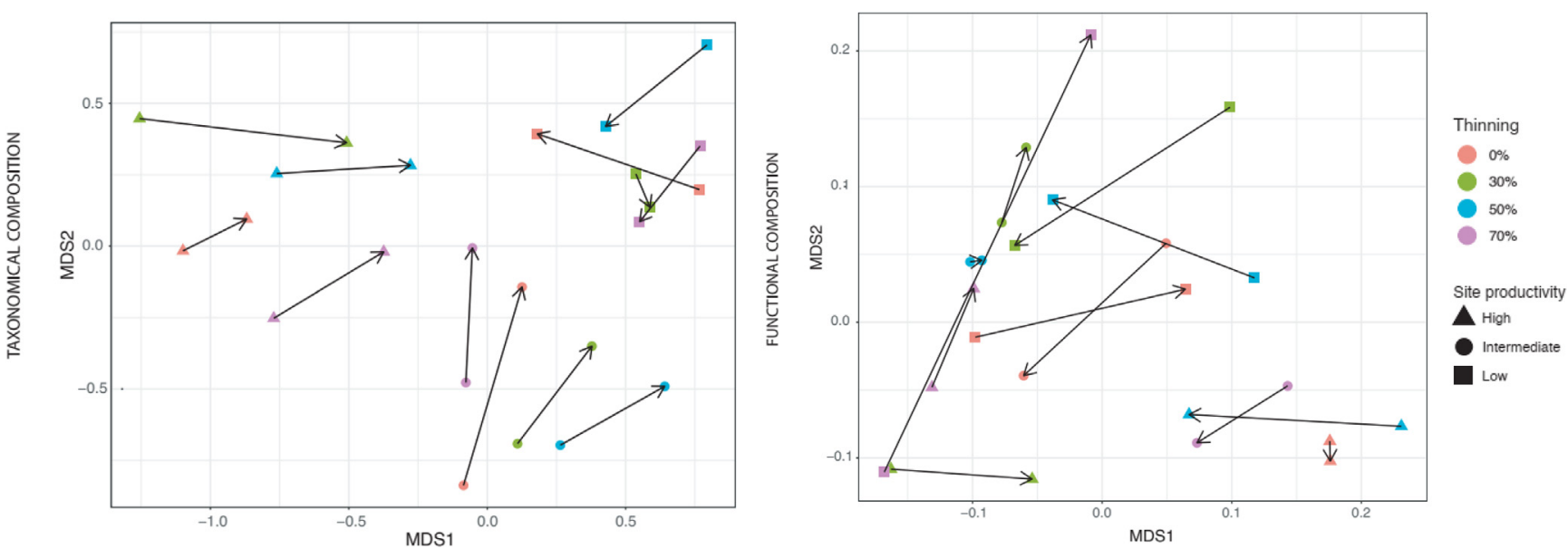

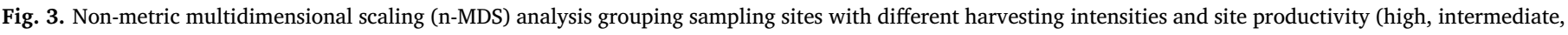
and low biomass growth) based on taxonomic and functional composition. 


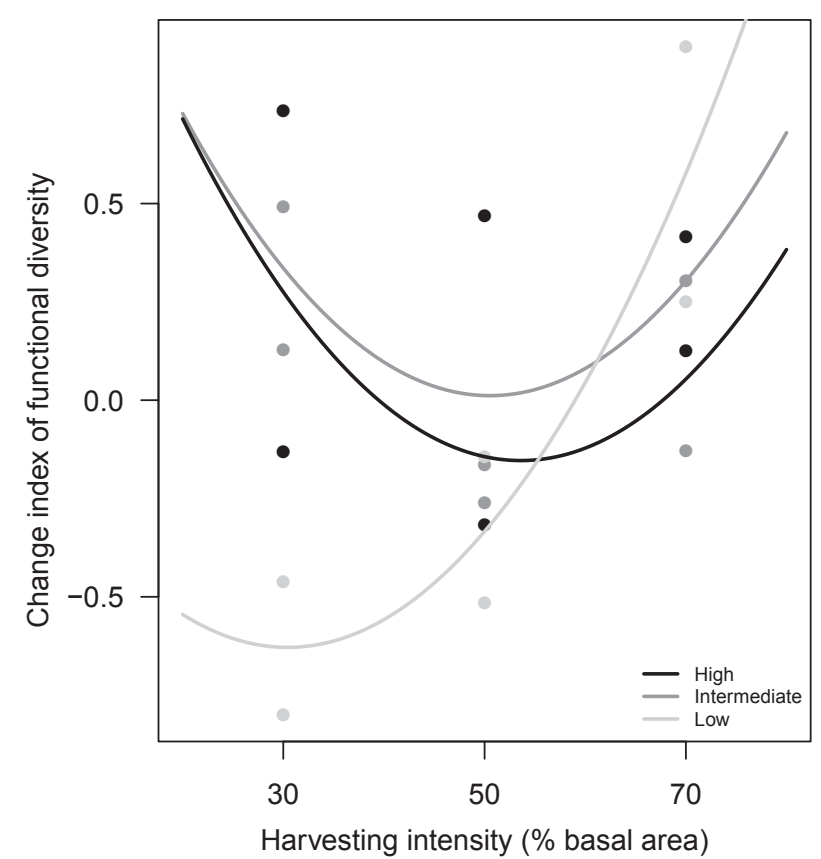

Fig. 4. Change index of functional diversity (Rao's Q) as a function of harvesting intensity (\% of basal area) and site productivity (high, intermediate, and low biomass growth). Positive values of CI indicate higher similarity with not-harvested sites, 0 indicates no change, negative values indicate differentiation from not-harvested sites.

In this sense, our results call for precaution in the generalization of conclusions and contributes to forest management by pinpointing that some important ecological responses to disturbances might be sitespecific.

Other key issue for planning sustainable natural resource management is the resilience of the system (Gunderson and Holling 2002; Folke et al. 2004). Interestingly, the resilience of community structure (i.e. resilience in taxonomic diversity) and of specific functional traits related to the leaf economic spectrum were not affected by harvesting intensity. Only site productivity (relative to firewood biomass) was an important factor for the resilience in taxonomic diversity; while both site productivity and harvesting intensity (and the interaction) were important factors accounting for differences in functional resilience (i.e. resilience in functional diversity), although with a low magnitude. Under lower and higher harvesting intensities functional diversity resembles a non-disturbed community more than under intermediate harvesting intensities in high and intermediate productivity sites. But in low productivity sites the response to lower and higher harvesting intensities presents opposite patterns, and sites with higher harvesting intensities were the ones that resembles the most to a non-disturbed community. Thus, we reject our hypothesis, as no clear pattern could be identified regarding important factors affecting the resilience of these woodlands to harvesting intensity.

Here we used the change index as a metric of resilience (Lipoma, 2018) by focusing on recovery based on a baseline from an undisturbed control treatment after 4 years since the disturbance. This index does not allow us to analyze the trajectory of each site after disturbance but rather compare it with a reference situation. In this sense, it gives useful information regarding the recovery component of resilience to harvesting for firewood (Ingrisch and Bahn, 2018), because treatments were completely randomized and control sites were part of the same stand as harvested sites, with similar ecological (species richness, seed bank) and climatic conditions. Other important consideration of our resilience analysis is that neither taxonomic nor functional diversity considers stand physiognomy. For example, many species may show similar abundance four years after harvesting because of their ability to resprout, but their architecture and their height might be different. This implies that other variable should also be considered when analyzing the return interval for firewood extraction (Goldenberg et al. 2020), and more studies should be conducted in this sense.

Considering the productive, social and environmental value of native shrublands of north Patagonia, the management of forests with energy purposes should be based on partial cuttings, leaving permanent forest cover to ensure the provision of ecosystem services and system sustainability (sensu National Law 26.331). In this way, harvesting in strips is an innovative management approach in north Patagonia that could be economically sustainable (Goldenberg et al. 2020). Also, in order to keep it environmentally sustainable, we recommend to use a low space factor (as the one used in our study) and place haversitng strips perpendicular to site slope to avoid wind and water erosion risk.

Finally, to effectively apply these results to forest management, information about ecosystem dynamic is needed. In the case of mixed woodlands in northwest Patagonia, a state and transition model had been proposed based on several background knowledge (Peri et al., 2017; Rusch et al., 2017). Our results shed light on the mechanisms behind the proposed positive and negative transitions of the reference state. For example, we show that in sites with greater firewood biomass production (high productivity), high harvesting intensities may not generate a negative transition from mixed shrubland to an open grasslands-woodland, as diversity peaked at the beginning and at the end of the experiment, and the traits that characterizes a shrub land resembled the control treatment in four years. But caution should be taken when managing a lower productivity woodland, as the response pattern is the opposite.

\section{Conclusion}

This study was designed to understand patterns and mechanisms of biodiversity response to harvesting for bioenergy in temperate woodlands (Goldenberg 2020), taking into consideration the complexity of the disturbance in space (harvesting intensity and site productivity) and time (resilience). We show evidence for the use of the dynamic equilibrium model (Huston 2014) in natural resources interventions considering both taxonomic and functional diversity and validate it as a useful tool for guiding management decisions in temperate woodlands. But when functional composition was analyzed, the response pattern was not as straightforward as the one found for diversity indices. For example, in sites with greater firewood biomass production (high productivity) under low harvesting intensities the community was characterized by a resource conservation strategy (high leaf chlorophyll content, shrubs), and higher harvesting intensity changed community towards a fast resource use strategy (lower leaf chlorophyll content, herbs). But the opposite response was found in low productivity sites. These results call for precaution in the generalization of conclusions and contributes to forest management by pinpointing that some important ecological responses to disturbances might be site-specific. Finally, the resilience of taxonomical diversity and functional composition was not affected by harvesting intensity. For functional diversity, we found that the capacity of these woodlands to resemble undisturbed sites four years after the elimination of the disturbance will depend on disturbance intensity and site productivity. Future studies considering longer periods of recovery time and site physiognomy are needed to effectively plan sustainable management, and the functional composition of the community needs to be addressed to ensure the analysis of he dynamic of the system.

\section{CRediT authorship contribution statement}

Verónica Chillo: Conceptualization, Methodology, Software, Data curation, Formal analysis, Investigation, Writing - original draft, Writing - review \& editing. Matías Goldenberg: Conceptualization, Methodology, Software, Writing - review \& editing. Néstor Pérez- 
Méndez: Software, Data curation, Formal analysis, Investigation, Writing - review \& editing. Lucas Alejandro Garibaldi: Funding acquisition, Supervision, Project administration, Conceptualization, Investigation, Writing - review \& editing.

\section{Declaration of Competing Interest}

The authors declare that they have no known competing financial interests or personal relationships that could have appeared to influence the work reported in this paper.

\section{Acknowledgments}

Marcos Nacif, Juan Agüero, Carolina Coulin, Sergio Torrego and Estefania Bianco Bueno helped with field work. We are grateful to Ubuntu's and R's developers and contributors for making science available to everyone. This work was supported by the Agencia Nacional de Promoción Científica y Tecnológica [grants PICT 20131079 and PICT 2016-0305].

\section{References}

Agard, J.B.R., Hubbard, H.R., Griffith, J.K., 1996. The relationship between productivity, disturbance and the diversity of Caribbean phytoplankton: applicability of Hustońs dynamic equilibrium model. J. Exp. Mar. Biol. Ecol. 202, 1.

Barton, K. 2019. Package MuMIn. https://cran.r-project.org/web/packages/MuMIn/ index.html.

Bates, D., Mächler, M., Bolker, B., Walker, S., 2014. Fitting linear mixed-effects models using lme4. J. Stat. Softw. 67. https://doi.org/10.18637/jss.v067.i01.

Botta-Dukat, Z., 2005. Rao's quadratic entropy as a measure of functional diversity based on multiple traits. J. Veg. Sci. 16, 533.

Cadotte, M.W., Carscadden, K., Mirotchnick, N., 2011. Beyond species: functional diversity and the maintenance of ecological processes and services. J. Appl. Ecol. 48, 1079.

Carrón, A.I., Garibaldi, L.A., Marquez, S., Fontenla, S., 2020. The soil fungal community of native woodland in Andean Patagonian forest: A case study considering experimental forest management and seasonal effects. For. Ecol. Manage. 461, 117955.

Chao, A., Chiu, C.H., Jost, L., 2014. Unifying species diversity, phylogenetic diversity, functional diversity, and related similarity and differentiation measures through Hill numbers. Ann. Rev. Ecol. Evolution Systematic 45, 297.

Chillo, V., Vázquez, D.P., Amoroso, M.M., Bennet, E.M., 2018. Land-use intensity indirectly affects ecosystem services mainly through plant functional identity in a temperate forest. Funct. Ecol. 32, 1390

Cingolani, A.M., Noy-Meir, I., Díaz, S., 2005. Grazing effects on rangeland diversity: a synthesis of contemporary models. Ecol. Appl. 15, 757.

Clarke, P.J., Knox, K.J.E., Wills, K.E., Campbell, M., 2005. Landscape patterns of woody plant response to crown fire: Disturbance and productivity influence sprouting ability. J. Ecol. 93, 544.

Connell, J.H., 1978. Diversity in tropical rain forests and coral reefs. Science 199, 1302.

Coulin, C., Aizen, M., Garibaldi, L., 2019. Contrasting responses of plants and pollinators to woodland disturbance. Austral Ecol. 44, 1040.

Davel, M., Ortega, A., 2003. Estimación del índice de sitio para pino oregón a partir de variables ambientales en la Patagonia Andina Argentina. Bosque 24, 55.

Duguid, M., Ashton, M., 2013. A meta-analysis of the effect of forest management for timber on understory plant species diversity in temperate forests. For. Ecol. Manage. $303,81$.

Folke, C., Carpenter, S., Walker, B., et al., 2004. Regime shifts, resilience, and biodiversity in ecosystem management. Annu. Rev. Ecol. Evol. Syst. 35, 557.

Garnier, E., Cortez, J., Billès, G., et al., 2004. Plant functional markers capture ecosystem properties during secondary succession. Ecology 85, 2630.

Goldenberg, M.G., 2020. Evaluación multidimensional de alternativas de manejo leñero de matorrales en Río Negro. Dissertation, Facultad de Agronomía, Universidad Nacional de. Buenos Aires.

Goldenberg, M.G., Oddi, F., Amoroso, M.M., Garibaldi, L.A., 2020. Effects of harvesting intensity and site conditions on biomass production of northern Patagonia shrublands. Eur. J. Forest Res. https://doi.org/10.1007/s10342-020-01292-6.

Gunderson, L.H., Holling, C.S., 2002. Panarchy: understanding transformations in systems of humans and nature. Island Press, Washington, DC, USA.

Haddad, N.M., Holyoak, M., Mata, T.M., Davies, K.F., et al., 2008. Species' traits predict the effects of disturbance and productivity on diversity. Ecol. Lett. 11, 348.

Holling, C.S., 1973. Resilience and stability of ecological systems. Annu. Rev. Ecol. Syst. $4,1$.

Huston, M., 2014. Disturbance, productivity, and species diversity: empiricism versus logic in ecological theory. Ecology 95, 2382.

Ingrisch, J., Bahn, M., 2018. Towards a comparable quantification of resilience. Trends Ecol. Evol. 33, 251.

IPBES, 2019. Global assessment report on biodiversity and ecosystem services of the
Intergovernmental Science-Policy Platform on Biodiversity and Ecosystem Services. Chapter 2: Status and trends; indirect and direct drivers of change. In: Brondizio, E.S. Settele, J., Díaz, S., Ngo, H.T. (Eds.), IPBES secretariat, Bonn, Germany.

Ishii, H.T., Maleque, M.A., Taniguchi, S., 2008. Line thinning promotes stand growth and understory diversity in Japanese cedar (Cryptomeria japonica D. Don) plantations. J Forest Res 13 (1), 73-78.

Johnstone, J.F., Allen, C.D., Franklin, J.F., et al., 2016. Changing disturbance regimes, ecological memory, and forest resilience. Front. Ecol. Environ. 14, 369.

Kohv, K., Zobel, M., Liira, J., 2013. The resilience of the forest field layer to anthropogenic disturbances depends on site productivity. Can. J. For. Res. 43, 1040.

Laliberté, E., Lambers, H., Norton, D.A., Tylianakis, J.M., Huston, M.A., 2013. A longterm experimental test of the dynamic equilibrium model of species diversity. Oecologia 171, 439.

Lavorel, S., Grigulis, K., 2012. How fundamental plant functional trait relationships scaleup to trade- offs and synergies in ecosystem services. J. Ecol. 100, 128.

Legendre, P., Legendre, L., 2012. Numerical Ecology, Third English Ed. Elsevier.

Lencinas, M.V., Martínez Pastur, G., Gallo, E., Cellini, J.M., 2011. Alternative silvicultural practices with variable retention to improve understory plant diversity conservation in southern Patagonian forests. For. Ecol. Manage. 262, 1236.

Lipoma, M.L. 2018. Resiliencia ecológica ante distintos usos de la tierra en el bosque chaqueño del noroeste de Córdoba, Argentina. 165pp. Universidad Nacional de Córdoba, Argentina.

Lipoma, M.L., Funes, G., Díaz, S., 2017. Fire effects on the soil seed bank and post-fire resilience of a semi-arid shrubland in central Argentina. Austral Ecol. 43, 46.

Mäkinen, H., Isomäki, A., Hongisto, T., 2006. Effect of half-systematic and systematic thinning on the increment of Scots pine and Norway spruce in Finland. Forestry 79 (1), 103-121.

Mayer, A.L., Tikka, P.M., 2006. Biodiversity conservation incentive programs for privately owned forests. Environ. Sci. Policy 9, 614.

Miedema, L.J., Capmourteres, V., Anand, M., 2019. Impact of land composition and configuration on the functional trait assembly of forest communities in southern Ontario. Ecosphere 10. https://doi.org/10.1002/ecs2.2633.

Mouchet, M., Villeger, S., Manson, N., et al., 2010. Functional diversity measures: An overview of their redundancy and their ability to discriminate community assembly rules. Funct. Ecol. 24, 867.

Nacif, M.E., Kitzberger, T., Garibaldi, L.A., 2020. Positive outcomes between herbivore diversity and tree survival: Responses to management intensity in a Patagonian forest. For. Ecol. Manage. 458, 117738.

Pérez-Harguindeguy, N., Díaz, S., Garnier, E., Lavorel, S., et al., 2013. New handbook for standardized measurement of plant functional traits worldwide. Aust. J. Bot. 61, 167.

Peri, P., López, D.R., Rusch, V., Rusch, G., et al., 2017. State and transition model approach in native forests of Southern Patagonia (Argentina): linking ecosystem services, thresholds and resilience. Int. J. Biodiversity Sci. Ecosyst. Services Management 13, 105.

Pinheiro J. , Bates, D., DebRoy, S., et al. 2018. nlme: Linear and Nonlinear Mixed Effects Models. R package version 3.1-137, https://CRAN.R-project.org/package $=$ nlme

Puettmann, K.J., Wilson, S.M., Baker, S.C., Donoso, P.J., et al., 2015. Silvicultural alternatives to conventional even-aged forest management - what limits global adoption? Forest Ecosystems 2, 8 .

R Core Team, 2017. R: A language and environment for statistical computing.

Reque, J.A., Sarasola, M., Elena, M., 2007. Caracterización silvícola de ñirantales del norte de la Patagonia para la gestión forestal sostenible Silvicultural. Bosque 28, 33.

Root, H., Betts, M.G., 2016. Managing moist temperate forests for bioenergy and biodiversity. J. For 114, 66

Rusch, V., López, D.R., Cavallero, L., Rusch, G.M., et al., 2017. Modelo de estados y transiciones de los ñirantales del NO de la Patagonia como herramienta para el uso silvopastoril sustentable. Ecología Austral 27, 266.

Shipley, B., Lechowicz, M.J., Wright, I., Reich, P.B., 2006. Fundamental trade-offs generating the worldwide leaf economics spectrum. Ecology 87, 535.

Stone, L., Gabric, A., Berman, T., 1996. Ecosystem resilience, stability, and productivity: Seeking a relationship. Am. Nat. 148, 892.

The Montreal Process, 2015. Criteria and Indicators for the Conservation and Sustainable Management of Temperate and Boreal Forests, 5th. The Montreal process, Hull.

Thomas, S.C., Halpern, C.B., Falk, D.A., Liguori, D.A., Austin, K.A., 1999. Plant diversity in managed forests: understory responses to thinning and fertilization. Ecol. Appl. 9, 864.

Thompson, I., Mackey, B., McNulty, S., Mosseler, A., 2009. Forest Resilience, Biodiversity, and Climate Change. A synthesis of the biodiversity/resilience/stability relationship in forest ecosystems. Secretariat of the Convention on Biological Diversity. Montreal. Technical Series 43, 67 pages.

Verschuyl, J., Riffell, S., Miller, D., Wigley, T.B., 2011. Biodiversity response to intensive biomass production from forest thinning in North American forests - A meta-analysis. For. Ecol. Manage. 261, 221.

Williams, L.J., Cavender-Bares, J., Paquette, A., Messier, C., Reich, P.B., 2020. Light mediates the relationship between community diversity and trait plasticity in functionally and phylogenetically diverse tree mixtures. J. Ecol. https://doi.org/10.1111/ 1365-2745.13346.

Wright, I.J., Sutton-Grier, A., 2012. Does the leaf economic spectrum hold within local species pools across varying environmental conditions? Funct. Ecol. 26, 1390.

Wright, I.J., Reich, P.B., Westoby, M., Ackerly, D.D., et al., 2004. The worldwide leaf economics spectrum. Nature $428,821$.

Zuur, A.F., Leno, E.N., Walker, N.J., Saveliev, A.A., Smith, G.M., 2009. Mixed Effect Models and Extentions in Ecology with R. Springer, Switzerland. 